\title{
Photo De-colorization of Cibacron Brilliant Yellow Dye Using ZnO Photo Catalyst under Sunlight
}

\author{
Namratha $\mathrm{K}^{1,2}$, Byrappa $\mathrm{K}^{1,2 *}$ and Deepthi $\mathrm{BK}^{1,2}$ \\ ${ }^{1}$ DOS in Earth Science Manasagangothri, University of Mysore, India \\ ${ }^{2}$ Center for Material Science and Technology, University of Mysore, India \\ *Corresponding author: K Byrappa, Center for Materials Science and Technology, University of Mysore, Vijnan Bhavan, P.B. No. 21, Manasagangothri, \\ Mysore-570006, India.
}

Submission: 豐January 25, 2018; Published: 㘹 February 23, 2018

\begin{abstract}
This research is mainly focused on evaluation of $\mathrm{ZnO}$ as a catalyst to decolorize cibacron brilliant yellow dye in presence of sunlight. The rate of de-colorization was monitored in terms of percentage transmission using UV-Vis Spectroscopy. The effects of different operating parameters which influence the de-colorization process such as initial dye concentration and catalyst loading has been systematically investigated. From the result it was observed that de-colorization process enhanced in the presence of sunlight yielding $90 \%$ efficiency at optimized condition i.e. dye concentration of about $12 \mathrm{ppm}$ with catalyst dosage $0.4 \mathrm{~g}$ for time duration of 180 minutes indicating right selection of operating parameter dosage allows in effective decolorization of cibacron brilliant yellow dye. Therefore $\mathrm{ZnO}$ can be effectively used as photo-catalyst which can exploit solar energy in order to improve efficiency of the photo-catalysis process.
\end{abstract}

Keywords: Photo-catalysis; ZnO; Cibacron brilliant yellow dye

\section{Introduction}

In recent years the use of semiconductors (SC) for decolorization of organic dyes which is referred to as heterogeneous Photo-catalysis process has attracted many researchers because of their ability to oxidize these dye stuffs into simpler mineralization products [1-2]. A Heterogeneous Photo-catalysis mainly proceeds in two pathways. In the first path way a semiconductor is illuminated with light source of energy greater than or equal to its band gap which results in excitation of electron from valence band to conduction band (Eq. 1.1) thus leaving behind a positive hole in the valence band, where in these generated charge carriers (electron and holes) migrate to the surface of the catalyst and initiate redox reaction [3-4] which ultimately result in production of reactive oxygen species as positive hole oxidize the water at the surface to form hydroxyl radical (Eq. 1.2) and electron in the conduction band is trapped by molecular oxygen which is reduced to form superoxide radical (Eq. 1.3). These reactive oxygen species are strong oxidizing agents which are capable of oxidizing organic compounds like dye into mineralization products such as $\mathrm{CO}_{2}$ and $\mathrm{H}_{2} \mathrm{O}$ (Eq. 1.4) without forming secondary pollutant.

$$
\begin{aligned}
& S C+h v \rightarrow h^{+}{ }_{v b}+e^{-}{ }_{c b} 1.1 \\
& h^{+}{ }_{v b}+H_{2} o \rightarrow H^{+}+O H \quad 1.2 \\
& e^{-}+O_{2} \rightarrow O_{2}^{-} 1.3
\end{aligned}
$$

$$
\mathrm{OH} / \mathrm{O}_{2}^{-}+\mathrm{Dye} \rightarrow \mathrm{CO}_{2}+\mathrm{H}_{2} \mathrm{O} \quad 1.4
$$

In the second pathway self sensitization of dye takes place because of the absorption of light energy (hv) which is lesser than the band gap of the semiconductor (Eq. 1.5) (i.e. wavelength in the visible light region) resulting in charge transfer (electron) from excited dye molecule to conduction band of the semiconductor, thus forming unstable cationic dye molecule (Eq. 1.6) which are constantly attacked by reactive oxygen species formed at the surface of the semiconductor (Eq. 1.7) [5-6].

$$
\begin{aligned}
& \text { Dye }+h v \rightarrow D^{*} e^{*} 1.5 \\
& D y e^{*}+S C \rightarrow D y e^{+}+e^{-} 1.6 \\
& D y e^{+}+\mathrm{OH} / \mathrm{O}_{2}^{-} \rightarrow \mathrm{CO}_{2}+\mathrm{H}_{2} \mathrm{O} \quad 1.7
\end{aligned}
$$

Several semiconductor metal oxides such as $\mathrm{TiO}_{2}, \mathrm{ZnO}, \mathrm{SnO}_{2}$ and $\mathrm{CeO}_{2}$ etc have been extensively studied for its potential application as Photo-catalyst in de-colorization of dyes [7]. However among all the semiconductors zinc oxide ( $\mathrm{ZnO}$ ) appears to be most efficient Photo-catalyst owing to its highly stable, non toxicity, high quantum efficiency, high efficiency in production of electrons, and low cost [8]. Although the application of $\mathrm{ZnO}$ for Photo-catalytic decolorization of organic dyes is limited because of narrow Photocatalytic region $(\lambda<400 \mathrm{~nm})$ due to its wide band gap energy around 
$3.3 \mathrm{ev}$ and electron hole recombination [9], its ability to absorb a small fraction of $(<5 \%)$ of incident solar radiation along with extended photo response by self sensitization capability of the model pollutant i.e. cibacron brilliant yellow, a textile dye having wavelength of about $404 \mathrm{~nm}$, thereby absorbing the light energy in visible region is the prime motivation of the present work to study the efficiency of $\mathrm{ZnO}$ as a catalyst in de-colorization of the cibacron brilliant yellow dye under sunlight and utilization naturally available oxygen that is present in atmosphere to combat electron hole recombination because dissolved oxygen act as electron scavenger by reducing it into superoxide radical, thus enhancing photo-catalytic activity.

\section{Chemical and Materials}<smiles>Cc1nn(-c2cc(Cl)c(S(=O)(=O)[O-])cc2Cl)c(O)c1N=Nc1cc(Nc2nc(Cl)nc(Nc3ccc(S(=O)(=O)O[NH3+])cc3)n2)ccc1S(=O)(=O)[O-]</smiles>

Figure 1: Molecular structure of cibacron brilliant yellow dye.

Textile dye, cibacron brilliant yellow (Figure 1) was obtained from Aldrich chem.co having molecular formula $\mathrm{C}_{25} \mathrm{H}_{15} \mathrm{Cl}_{3} \mathrm{~N}_{9} \mathrm{Na}_{3} \mathrm{O}_{10} \mathrm{~S}_{3}$ with color index number $18972, \lambda_{\max }=404 \mathrm{~nm}$ and molecular weight $=872.97 \mathrm{~g} / \mathrm{mol}$. $\mathrm{ZnO}$ is procured from Ranbaxy and used without any further purification. The water used in all the experiment is nano pure water with a resistivity of $18.2 \mathrm{M} \Omega \mathrm{cm}$ purified by PURELAB Option Q7, ELGA, UK. Percentage transmission was analyzed using UV-Vis Spectroscopy.

\section{Experiment}

Cibacron brilliant yellow dye was used as model pollutant to determine the de-colorization efficiency of $\mathrm{ZnO}$. In order to study the effect catalyst dosage and concentration variation batch experiments with working volume of about $250 \mathrm{ml}$ were conducted by varying catalyst dosage (i.e. $0.1,0.2,0.3,0.4$ and $0.5 \mathrm{~g}$ ) and dye concentration $(6,12,18,24$ and $30 \mathrm{ppm})$. De-colorization process was initiated by exposing reaction mixture containing dye solution and catalyst $\mathrm{ZnO}$ to direct sunlight which were carried out for about 180 minute. At regular interval of time (30 minutes) $2-3 \mathrm{ml}$ of aliquots were collected and were immediately centrifuged to separate the catalyst particles. Then absorption spectra of sample solution were recorded at $\lambda \max 404 \mathrm{~nm}$ with UV-Vis Spectrophotometer. The rate of de-colorization was studied in terms of changes in percentage transmission.

\section{Results and Discussion}

\section{Catalyst loading effects on photocatalyst de-colorization of cibacron brilliant yellow dye}

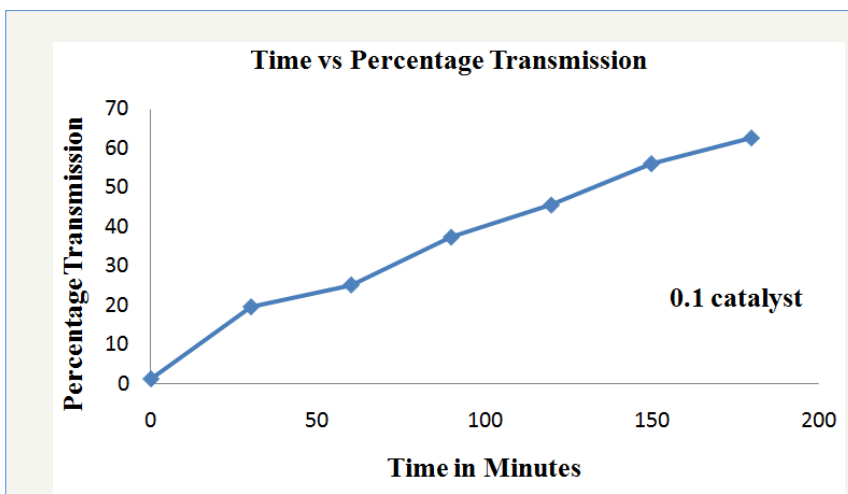

Figure 2: Effect of catalyst loading rate $(0.1 \mathrm{~g})$ in decolorization of cibacron brilliant yellow dye.

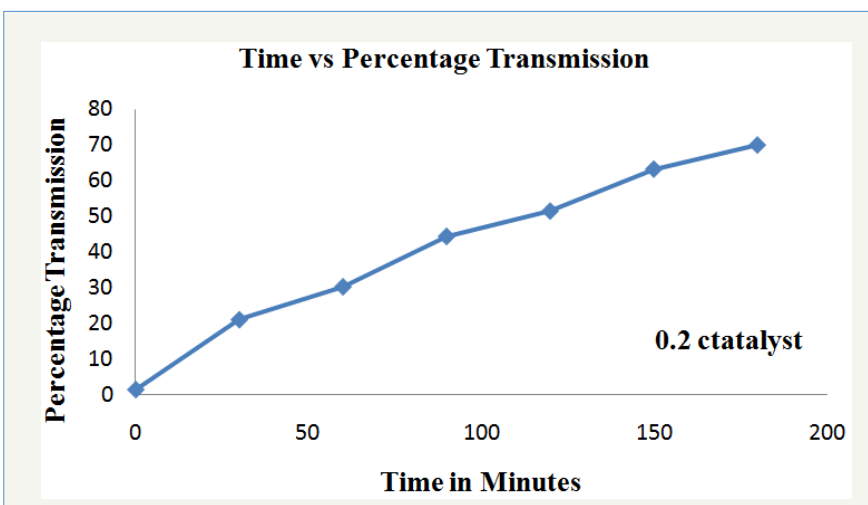

Figure 3: Effect of catalyst loading rate $(0.2 \mathrm{~g})$ in decolorization of cibacron brilliant yellow dye.

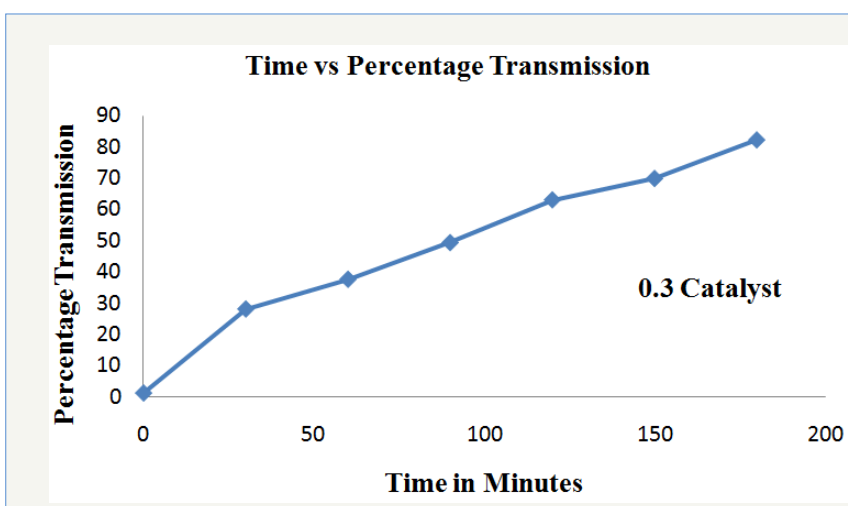

Figure 4: Effect of catalyst loading rate (0.3g) in decolorization of cibacron brilliant yellow dye.

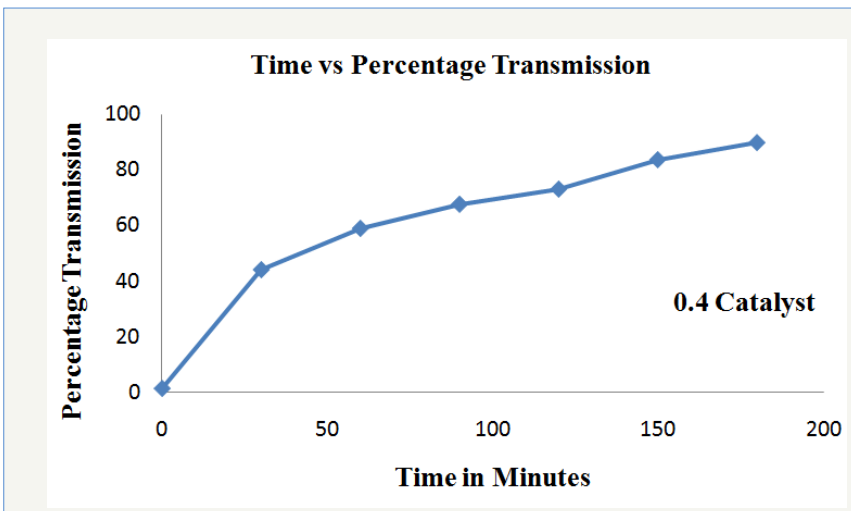

Figure 5: Effect of catalyst loading rate $(0.4 \mathrm{~g})$ in de-colorization of cibacron brilliant yellow dye. 


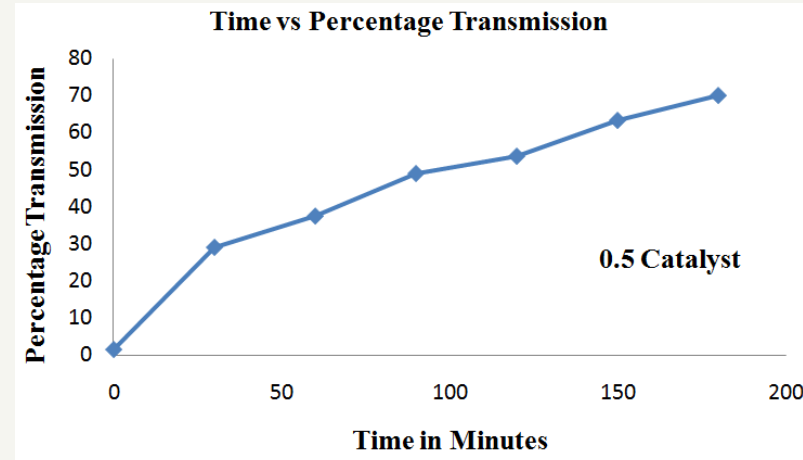

Figure 6: Effect of catalyst loading rate $(0.5 \mathrm{~g})$ in decolorization of cibacron brilliant yellow dye.

In order to study the effect of catalyst loading rate, $\mathrm{ZnO}$ dosage was varied from $0.1 \mathrm{~g}, 0.2 \mathrm{~g}, 0.3 \mathrm{~g}, 0.4 \mathrm{~g}$ to $0.5 \mathrm{~g}$ keeping dye concentration constant at $12 \mathrm{ppm}$ for time duration of about 180 minutes (Figure 2-6). From the results it was observed that when the amount catalyst increased from $0.1 \mathrm{~g}$ to $0.4 \mathrm{~g}$, percentage transmission reached $90 \%$ for optimized condition i.e. $0.4 \mathrm{~g}$ which is attributed to increase in generation hydroxyl and superoxide radical due availability of more number of active sites on the surface of $\mathrm{ZnO}$ which are primary oxidants and take part in actual de-colorization of dye molecules [10]. However when the amount of catalyst were further increased from $0.4 \mathrm{~g}$ to $0.5 \mathrm{~g}$ percentage transmission was found to decrease, which is presumed because of the hindrance in the transmission of sunlight into the reaction mixture due to opacity caused by the suspension of more amount of $\mathrm{ZnO}$ resulting in lesser generation of reactive oxygen species [11]. Thus it was inferred that higher catalyst dosage is not recommended both in the terms of aggregation as well as reduction in irradiation of light due light scattering. Therefore determination of optimum amount of catalyst is foremost important for efficient de-colorization of cibacron brilliant yellow dye in the presence of $\mathrm{ZnO}$ as catalyst.

\section{Concentration variation effects on photocatalyst de- colorization of cibacron brilliant yellow dye}

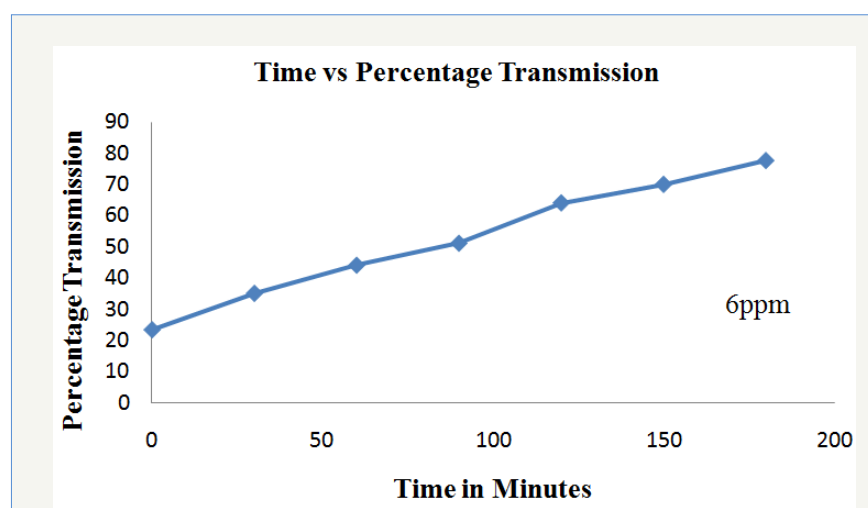

Figure 7: Effect of concentration variation (6ppm) in decolorization of cibacron brilliant yellow dye.

The effect of initial concentration of cibacron brilliant yellow on Photo-catalytic de-colorization was studied by varying initial concentration from $6 \mathrm{ppm}, 12 \mathrm{ppm}, 18 \mathrm{ppm}, 24 \mathrm{ppm}$ to $30 \mathrm{ppm}$ keeping catalyst dosage constant at $0.4 \mathrm{~g}$ for time duration of about 180 minutes (Figure 7-11). From the results it was observed that initially by increasing the concentration from $6 \mathrm{ppm}$ to $12 \mathrm{ppm}$ percentage transmission reached $90 \%$ indicating that optimum amount of catalyst should be applied to a particular concentration for better efficiency of the process. However when the concentration was further increased from $18 \mathrm{ppm}$ to $30 \mathrm{ppm}$ percentage transmission was found to decrease because at higher concentration the catalytic activity of $\mathrm{ZnO}$ is reduced due adsorption of more dye molecules to catalyst surface since the rate of decolorization is mainly dependent on generation of reactive oxygen species [12]. Furthermore at higher concentration at large amount of incident light might be utilized for excitation of dye molecules rather than generation hydroxyl or superoxide radical resulting in lesser efficiency of process.

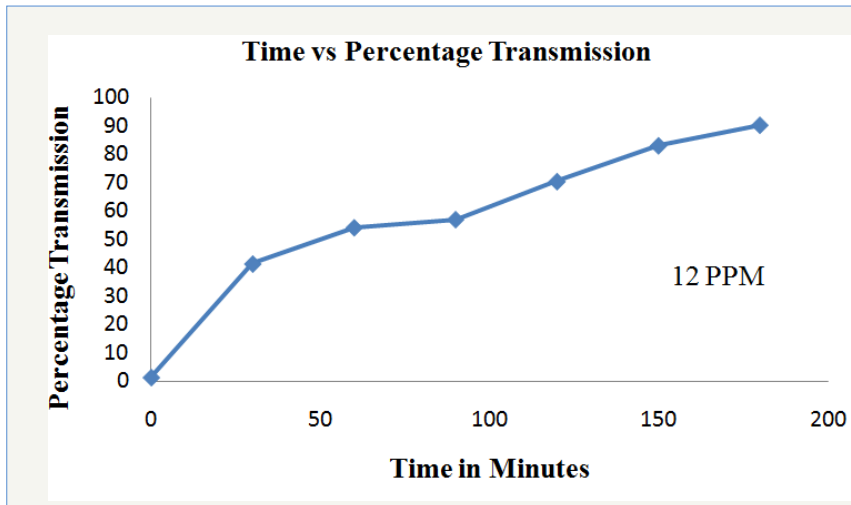

Figure 8: Effect of concentration variation (12ppm) in decolorization of cibacron brilliant yellow dye.

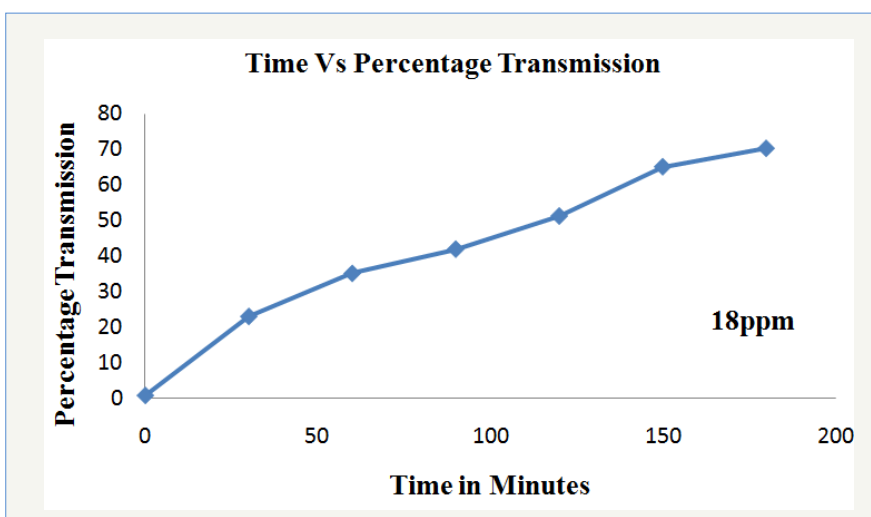

Figure 9: Effect of concentration variation (18ppm) in decolorization of cibacron brilliant yellow dye.

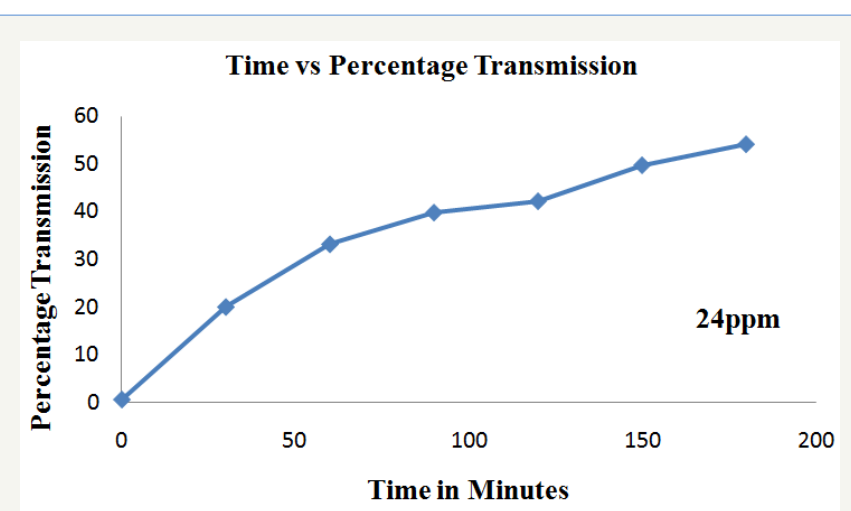

Figure 10: Effect of concentration variation (24ppm) in decolorization of cibacron brilliant yellow dye. 


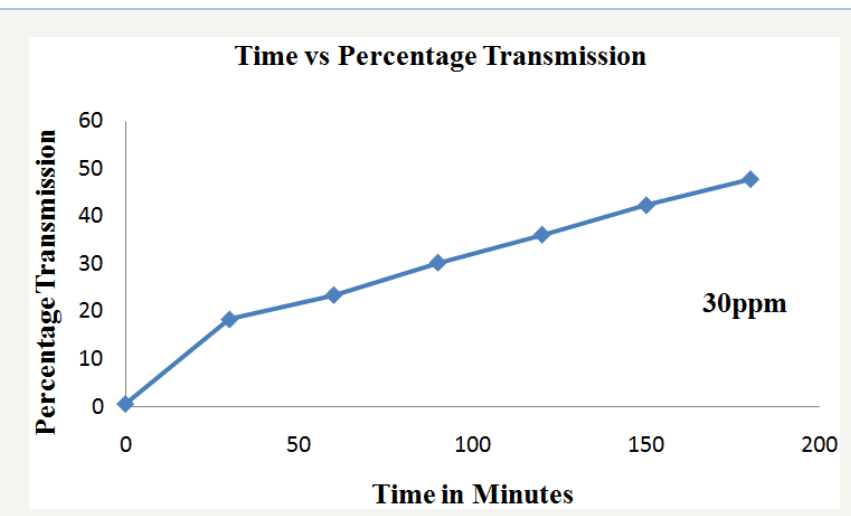

Figure 11: Effect of concentration variation (30ppm) in decolorization of cibacron brilliant yellow dye.

\section{Conclusion}

The scope of the present study was to evaluate the efficiency of $\mathrm{ZnO}$ as a catalyst to de-colorization of cibacron brilliant yellow dye under sunlight. Therefore photo-catalytic activity of $\mathrm{ZnO}$ was tested by varying operating parameter such as catalyst loading rate and initial dye concentration. From the study it was observed that de-colorization process was mostly initiated by the reactive oxygen species whose generation mainly depends on catalyst dosage, dye concentration and irradiation source i.e. sunlight, than self sensitization capacity of dye molecules since efficiency of the process decreased at higher concentration of dye solution. Therefore we can infer that $\mathrm{ZnO}$ can be effectively used as photocatlyst for decolorization of textile dye cibacron brilliant yellow.

\section{References}

1. Bora LV, Mewada $\mathrm{RK}$ (2016) $\mathrm{TiO}_{2}$ and $\mathrm{ZnO}$ as Heterogeneous Photocatalysts for Wastewater Treatment. International Research Journal of Engineering and Technology 3(2): 1610-1616.
2. Fahim Y, Hadi S, Jawad A, Sadoon A, Salih A (2014) Photo-catalytic decolorization of methylene blue dye by zinc oxide powder. Journal of Babylon University/Pure and Applied Sciences 9(22): 2508-2515.

3. Falaras P, Nolan N, Pelaez M, Pillai S, Seery M, et al. (2012) A review on the visible light active titanium dioxide photo catalysts for environmental application. Journal of Applied Catalysis B: Environmental 125: 331-349.

4. Pasternak S, Paz Y, Rochkind M (2015) Using dyes for evaluating photo catalytic properties: a critical review. Molecules 20(1): 88-110.

5. Dixit R, Pare B, Raghuvanshi D, Swami D (2013) Decolorization and mineralization of hazardous brilliant cresyl blue dye utilizing visible light and $\mathrm{Tio}_{2}$ as photocatalyst. Int J Chem Sci 11(4): 1876-1890.

6. Jincai Z, Wei Z, Xiangzhong L (2002) Visible light-sensitized semiconductor photo catalytic degradation of 2,4-dichlorophenol. Science in China Series B: Chemistry 45(4): 421-425.

7. Adil SF, Khan MM (2015) Metal oxides as photocatalyst. Journal of Saudi Chemical Society 19(5): 462-464.

8. Glahl O, Hossinl H, Rezaee R, Safari M, Soltanl RDC, et al. (2015) Application of experimental design approach for optimization of the photocatalytic degradation of humic substances in aqueous solution using immobilized $\mathrm{ZnO}$ nanoparticles. Journal of Advance in Environmental Health Research 3(3): 154-163.

9. Bakr MF, Elmorsi TM, Elsayed MH (2017) Na doped ZnO nanoparticles assisted photo catalytic degradation of congo red dye using solar light. American Journal of Chemistry 7(2): 48-57.

10. Kabra BV, Mehta V, pamecha K (2016) Photocatalytic degradation of commercial textile azo dye reactive blue 160 by heterogeneous photo catalysis. Advance in Applied Science Research 7(3): 95-101.

11. Abd E, Anbari RL, Obaidy AHA (2016) Photocatalytic activity of $\mathrm{Fe}_{3} \mathrm{O}_{4}$ under solar radiation. Mesopotamia Environmental Journal 2(4): 41-53.

12. Arabi AM, Mohammadzadeh S, Khosravi Nikuo MR, Olya ME, Shariati A (2015) Synthesis, characterization and application of ZnO-Ag as a nano photo catalyst for organic compounds degradation, mechanism and economic study. J Environ Sci 35: 194-207.

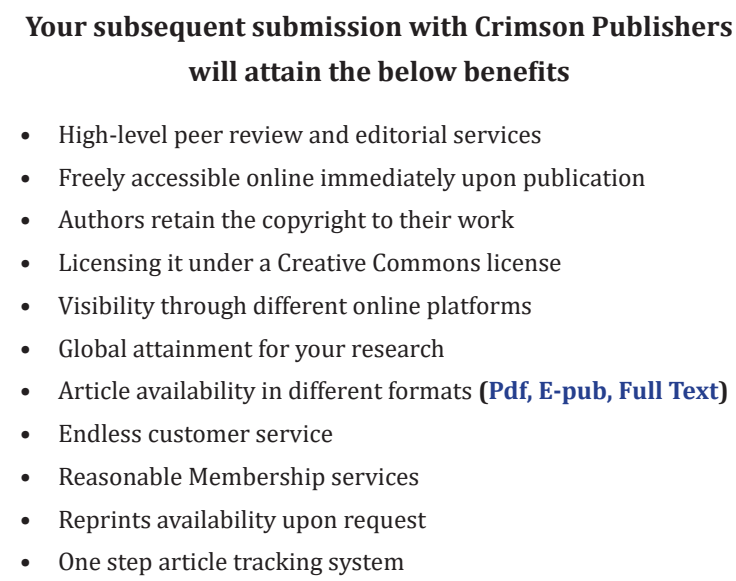

- High-level peer review and editorial services

- Freely accessible online immediately upon publication

- Authors retain the copyright to their work

- Licensing it under a Creative Commons license

- Visibility through different online platforms

- Global attainment for your research

- Article availability in different formats (Pdf, E-pub, Full Text)

- Endless customer service

- Reasonable Membership services

- Reprints availability upon request

- One step article tracking system 